\title{
AVALIAÇÃO DAS PERDAS HÍDRICAS NA REDE DE ABASTECIMENTO DE ÁGUA DA ZONA URBANA DO MUNICÍPIO DE TIMON/MA: COMPARATIVOS ENTRE A MACROMEDIÇÃO E A MICROMEDIÇÃO ${ }^{1}$
}

\author{
Rafael Fontenele Sampaio, UNIFSA ${ }^{2}$ \\ Ricardo Augusto de Carvalho Sá, UNIFSA ${ }^{3}$ \\ Laydson Moura Fernandes Amorim, UNIFSA ${ }^{4}$ \\ Hebert Rodrigues Araujo, UNIFSA ${ }^{5}$ \\ Tássio Tanic Leite Lima, UNIFSA ${ }^{6}$
}

\section{RESUMO}

Nas décadas de 1970 e 1980 o saneamento básico no Brasil teve sua importância levada em consideração com investimento nunca visto anteriormente, como a necessidade inicial era abastecer as residências de água tratada e própria para o consumo, o setor de abastecimento de água teve um olhar especial em relação ao tratamento de esgoto e drenagem. Percebeu-se que fazer todo o tratamento adequado de acordo com as normas tinha um preço muito alto, além da falta de instrumentos para quantificar o que era produzido e o que era consumido pela população, tinha outros aspectos que geravam muitas perdas no sistema como: ligações clandestinas, vazamentos entre outros. Atualmente as empresas, na grande maioria privadas, responsáveis pelo sistema de saneamento nas grandes cidades, fazem um rigoroso controle destas perdas, onde um dos instrumentos principais para minimizar esta problemática é o controle do balanço hídrico, através de macromedidores e micromedidores a concessionária tem um quantitativo real do que foi produzido e consumido pela população, assim identificando e intervindo nas perdas. Com o objetivo de quantificar as perdas hídricas na rede de abastecimento do município, realizou-se uma pesquisa nos banco de dados da concessionaria onde pudemos perceber que, mesmo com os avanços tecnológicos e o rigoroso controle, ainda há um alto percentual de perdas, porém ficou abaixo da média nacional.

Palavras-Chave: Saneamento Básico. Abastecimento. Balanço Hídrico. Perdas. Controle de Perdas

\footnotetext{
1 Trabalho apresentado no Congresso Brasileiro Ciência e Sociedade (CBCS 2019), promovido pelo Centro Universitário Santo Agostinho, de 03 a 05 de outubro de 2019, em Teresina-PI.

2 Graduando em Engenharia Civil, Centro Universitário Santo Agostinho, raphaelfsampaio@ hotmail.com

3 Graduando em Engenharia Civil, Centro Universitário Santo Agostinho, ricardo.carvalhosa@ hotmail.com

4 Mestre em Agronomia, Universidade Federal do Piauí, laydsonmoura@ hotmail.com

5 Graduando em Engenharia Civil, Centro Universitário Santo Agostinho, hebertrodriguesss@outlook.com

6 Graduando em Engenharia Civil, Centro Universitário Santo Agostinho, tassiotanic1@gmail.com
}

ISBN: 978-65-80968-11-4 DOI: $10.17648 /$ cbcs-2019-110678 


\section{CONGQEESSOCIENCIAESOCIEDADE \\ Inovação, Diversidadie e Sustentahilitidade}

ANAIS CBCS 2019 | 3 a 5 de outubro de 2019 | Centro Universitário Santo Agostinho - Teresina - PI

\section{INTRODUÇÃO}

O Brasil é um dos países que mais possui água doce no mundo, mesmo assim enfrenta grandes dificuldades como falta de água e sistema de abastecimento público, a distribuição de água no Brasil é bem desigual, a região norte do país é a que possui a maior quantidade de água, mesmo assim não fica livre dessas dificuldades, a região nordeste é a que possui menos recursos hídricos (BONATI, 2007).

O acelerado crescimento populacional desordenado e muito acentuado vem contribuindo diretamente para a escassez hídrica, fazendo com que a população passe a pensar mais sobre vulnerabilidade do sistema, a má distribuição e a natureza finita deste recurso natural (CHEUNG, 2013).

Todo o volume hídrico que abastece as cidades passa por um rigoroso e complexo e rigoroso tratamento físico e químico para deixar própria ao consumo humano, sendo realizado por empresas que necessitam de um sistema completo para a captação, purificação, armazenamento e distribuição aos centros populacionais, todos esses instrumentos compõem o que conhecemos de Sistema de Abastecimento de Água (SAA) (MINISTÉRIO DAS CIDADES, 2013).

Imagem 1. Sistema de Abastecimento de Água (SAA)

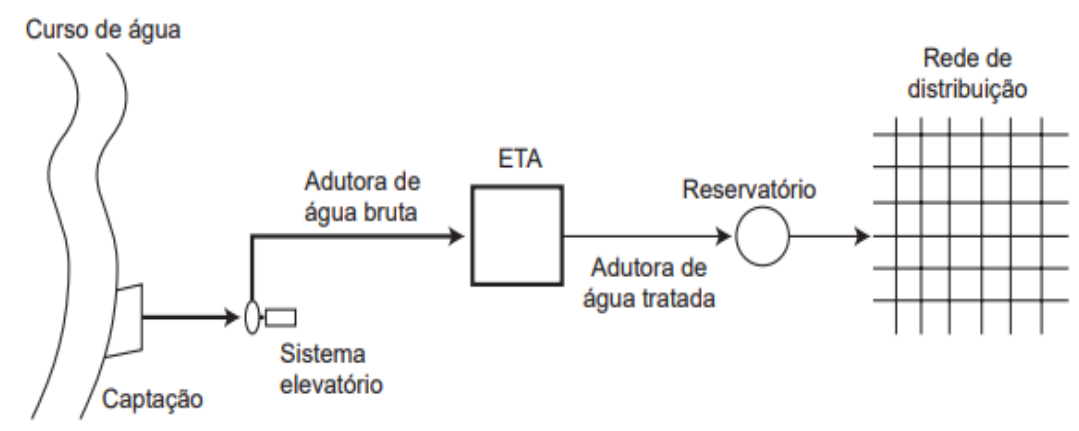

Fonte. Sistema Nacional de Informações sobre Saneamento (SNIS). 


\section{CONQGEESOO CIENCIAESOCIEDADE Inovação, Diversidaale e Sustentalililitadie}

ANAIS CBCS 2019 | 3 a 5 de outubro de 2019 | Centro Universitário Santo Agostinho - Teresina - P

O Sistema de Abastecimento de Água (SAA) deve garantir à população água em quantidade e qualidade de forma suficiente para que a população possa suprir suas necessidades. Porém, devido aos problemas de escassez, estiagens, poluição e deterioração dos mananciais, o problema de abastecimento torna-se de conhecimento público gerando os desafios para gestão dos recursos hídricos (GONÇALVES et. al., 2015).

A Associação Brasileira de Engenharia Sanitária e Ambiental diz que as perdas de água no abastecimento sistema é responsável por dificultar um serviço de qualidade. Dados da associação mostram que a média do índice de perda de abastecimento no Brasil é de 40\%, número considerado bastante alto, porém em algumas cidades o índice supera os 60\% (ABES, 2013).

As perdas de água no abastecimento público corresponde a quantidade de água que não é contabilizada, essas perdas podem ser de dois tipos, as perdas reais ou físicas que é o volume de água não consumido, ou seja, é o volume de água que se perde na distribuição e não passa pelo hidrômetro do consumidor, e as perdas aparentes ou não físicas que é quando a água é consumida mas não é registrada por algum motivo, ligações irregulares, modificações na posição do hidrômetro são alguns exemplos (BONATI, 2007).

Tabela 1. Demonstrativo do balanço hídrico (IWA)
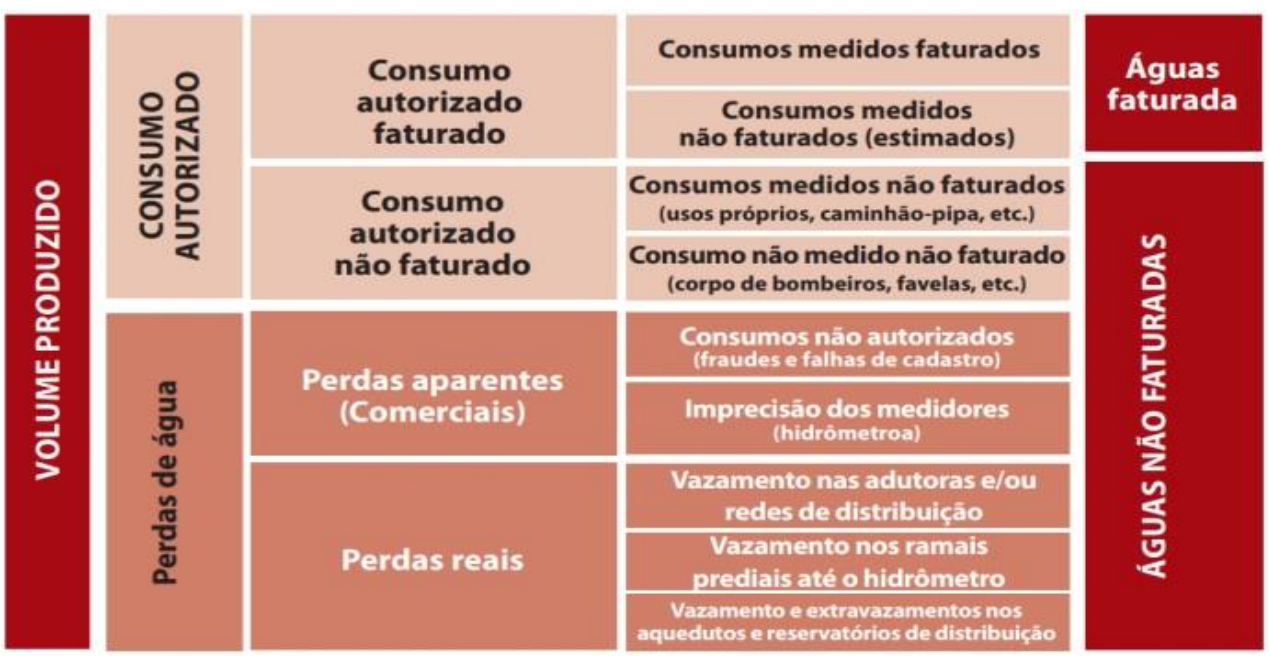

Fonte. Sistema Nacional de Informações sobre Saneamento (SNIS). 


\section{CONQEESSOC CIENCIASSOCIEDADE

ANAIS CBCS 2019 | 3 a 5 de outubro de 2019 | Centro Universitário Santo Agostinho - Teresina - PI

\section{METODOLOGIA}

O presente trabalho caracteriza-se como uma pesquisa quantitativa e descritiva, através dos dados pesquisados na concessionaria AEGEA, responsável pelo abastecimento de água no município de Timon/MA, conseguimos quantificar o balanço hídricos nos meses de maio, junho e julho do ano de 2019 , através dos volumes de águas produzidos e faturados.

O Grupo AEGEA através do sistema de parceria público privada iniciou a administração do sistema de saneamento básico da cidade no ano de 2016, inicialmente apenas na captação, tratamento e distribuição de água, e atualmente no tratamento de esgoto e resíduos sólidos.

A cidade de Timon no estado do Maranhão conta com uma população estimada em 2019 de 169.107 pessoas, atualmente na zona urbana $100 \%$ da população é abastecida através do sistema de abastecimento de água administrado pelas Águas de Timon (AEGEA), 92\% dos domicílios da zona urbana contam com instrumentos de medição, micromedidores, conhecidos como hidrômetros.

A captação hídrica na cidade é mista, onde parte da população da zona urbana é abastecida através dos poços tubulares e outra parte através do rio Parnaíba, porém ambos os processos passam por um rigoroso tratamento químico e físico antes de serem distribuídos.

Com uso de tabelas e gráfico pudemos mensurar o percentual hídrico perdido no processo de distribuição na cidade e através de dados obtidos em plataformas de monitoramento específicos de saneamento básico podemos fazer um comparativo das perdas em relação à média nacional.

\section{RESULTADOS E DISCUSSÃO}

Através dos dados obtidos na concessionária, percebemos que grande parte do volume de água produzido não chega ao seu destino final, e se chega este não é quantificado. As perdas no sistema de distribuição de água ainda é e será um grande desafio para as concessionárias administradoras do sistema. 


\section{gongersSO CIENCIASSOCIEDADE Inovação, Diversidaale e Sustentahilitilatie}

ANAIS CBCS 2019 | 3 a 5 de outubro de 2019 | Centro Universitário Santo Agostinho - Teresina - PI

$\mathrm{Na}$ cidade de Timon/Ma, este percentual se mostrou um pouco abaixo da média Nacional, porém ainda muito alto levando em consideração ao custo de captação, tratamento e distribuição, porém altos investimento para quantificar os volumes de águas através do balanço hídricos foram realizados na cidade.

Como podemos perceber na tabela $\mathbf{2}$, atualmente a concessionária tem o total controle sobre esses volumes, mas ainda enfrenta dificuldades em minimizar as perdas. Os fatores como grande extensão territorial da cidade, crescimento desordenado da cidade, ligações clandestinas e desvios (by pass), ainda dificultam a intervenção e recuperação dos volumes perdidos.

Os volumes de águas produzidos seguem uma constante nos três meses pesquisados, chegando quase 1,5 milhões de metros cúbicos ao mês, percebemos também que o percentual de água perdida se manteve constante no trimestre, ou seja, mesmo sendo um percentual elevado mostrou que não houveram perdas através de vazamentos significativos no período, pois manteve a média esperada pela concessionária.

Tabela 2. balanço hídricos nos meses de Maio, Junho e Julho

\begin{tabular}{|c|c|c|c|}
\hline TIMON -MA & mai/19 & jun/19 & jul/19 \\
\hline Volume de Água Produzido $\left(\mathrm{m}^{3}\right)$ & 1.436 .586 & 1.421 .124 & 1.529 .859 \\
\hline Volume de Água Importado $\left(\mathrm{m}^{3}\right)$ & 0 & 0 & 0 \\
\hline Volume de Água Micromedido $\left(\mathrm{m}^{3}\right)$ & 521.980 & 514.954 & 525.764 \\
\hline Volume de Água Estimado $\left(\mathrm{m}^{3}\right)$ & 48.808 & 44.380 & 45.850 \\
\hline Volume de Água Recuperado $\left(\mathrm{m}^{3}\right)$ & 5.335 & 2.165 & 4.274 \\
\hline Volume de Água Especial $\left(\mathrm{m}^{3}\right)$ & 252.501 & 257.346 & 251.230 \\
\hline Perdas na Distribuição - Física (\%) & $42,70 \%$ & $42,50 \%$ & $46,90 \%$ \\
\hline Volume de Água Perdido $\left(\mathrm{m}^{3}\right)$ & 613.296 & 604.444 & 727.015 \\
\hline Perdas na Distribuição - Média Nacional (\%) & $51,60 \%$ & $51,80 \%$ & $55,80 \%$ \\
\hline
\end{tabular}

Fonte. Timon/MA, Águas de Timon (AEGEA). 


\section{conghESSOCIENCIAESOCIEDADE Inovação, Diversidadie e Sustentahilitidade}

ANAIS CBCS 2019 | 3 a 5 de outubro de 2019 | Centro Universitário Santo Agostinho - Teresina - PI

Com pesquisas feitas através da plataforma SNIS, podemos comparar o percentual de perdas do município de Timon no estado do Maranhão com o percentual de perdas a nível nacional no mesmo período e constatamos que média nacional se mostrou mais elevada que a cidade estudada. Gráfico1.

Gráfico 1. Comparativo das Perdas entre a cidade de Timon e a média nacional

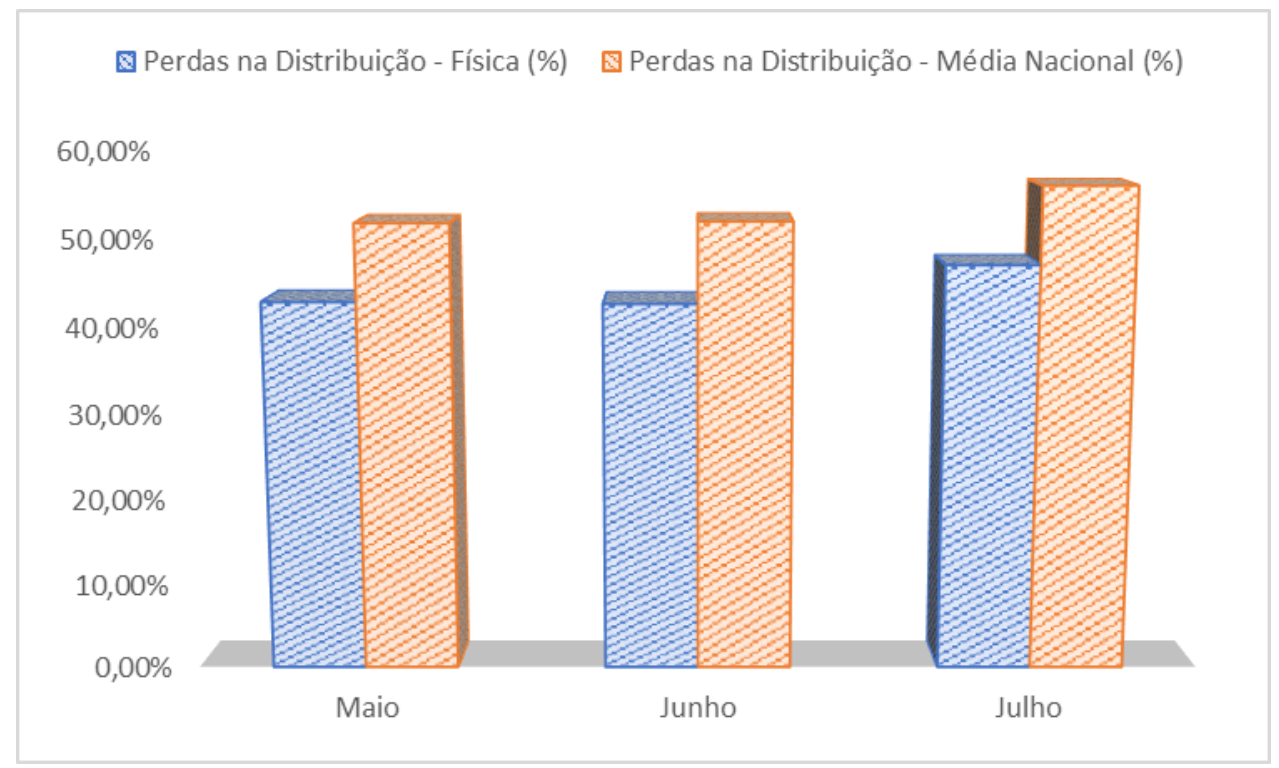

Fonte. Timon/MA, Águas de Timon (AEGEA), (SNIS).

Com os dados obtidos, a concessionária pode criar uma política de prevenção e intervenção de perdas, através do uso de tecnologia para quantificar os volumes e na fiscalização para coibir os desvios.

Como podemos ver no gráfico 2 , houve um retorno destas perdes através da fiscalização e intervenção e aplicações de multas, porém não chegou a 1\%, se tornando desprezível. A empresa administradora ao identificar uma perda aparente, ou seja, um volume de água que chegava ao consumidor e não era faturado, através de dados obtidos no balanço hídrico, é estipulado um 


\section{conghESSO CIENCIAESOCIEDADE

ANAIS CBCS 2019 | 3 a 5 de outubro de 2019 | Centro Universitário Santo Agostinho - Teresina - PI

período que esse volume estava sendo desviado e aplica uma multa proporcional ao valor do metro cúbico cobrado usualmente.

Gráfico 2. Volumes hídricos recuperados

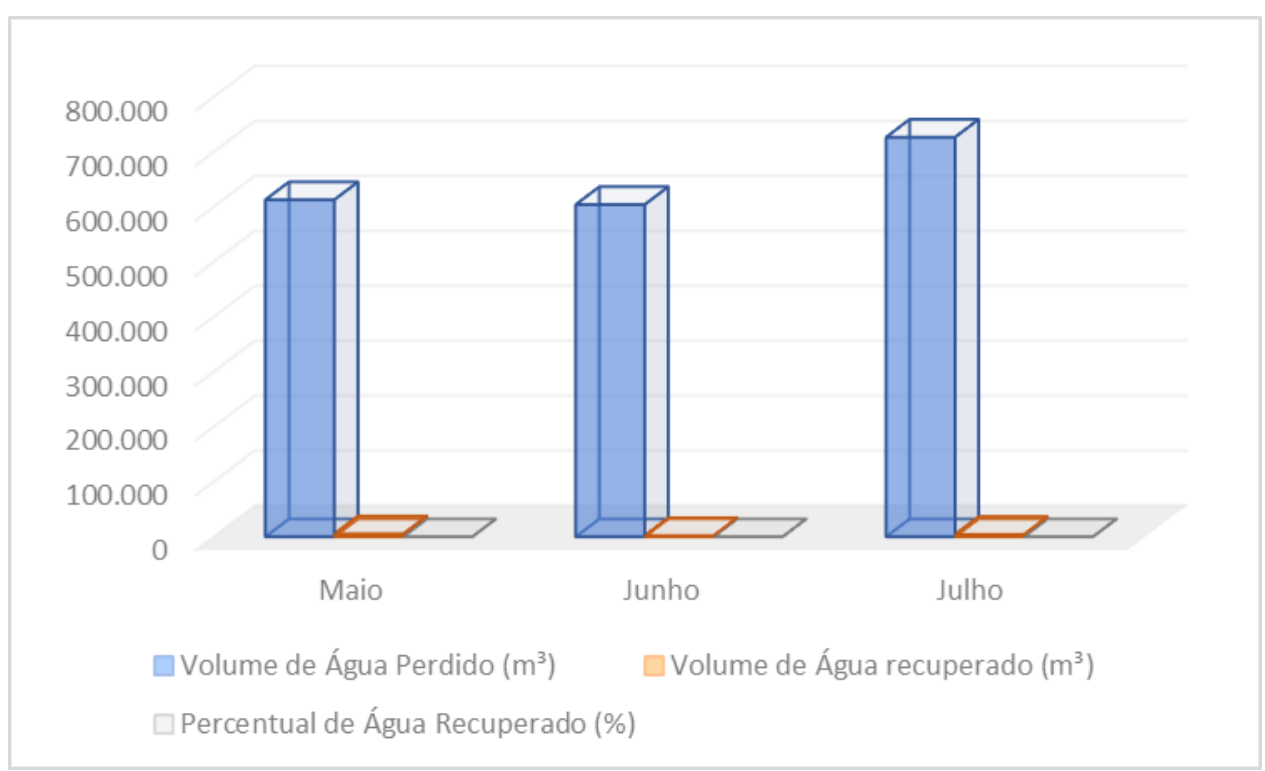

Fonte. Timon/MA, Águas de Timon (AEGEA).

\section{CONSIDERAÇÕES FINAIS}

Concluímos que, mesmo com os grandes investimentos em saneamento básico, especificamente o setor de abastecimento de água, com aquisições de equipamentos de altas precisões e com o controle rigoroso das perdas através do balanço hídrico, o percentual ainda é bastante elevado.

Comparando a cidade de Timon com a média nacional, percebemos um leve percentual a menos nas perdas. Atualmente a concessionária faz usos de macromedidores dos tipos mecânicos e ultrassónicos, medidores esses com um nível de precisão elevado. 
ANAIS CBCS 2019 | 3 a 5 de outubro de 2019 | Centro Universitário Santo Agostinho - Teresina - P

Percebemos também que a população precisa se conscientizar sobre a importância do bom uso deste recurso finito, pois os dados mostraram que grande parte deste percentual de perdas estão relacionados com o volume que chega a residencia e não é faturado, podendo este está sendo desviado.

Porém o sistema de balanço hídrico, através da macromedição e micromedição, se mostrou eficiente, pois a concessionaria está a pouco mais de 3 anos operando o sistema e já pode fazer grandes investimento e vem diminuindo gradativamente essas perdas ano a ano.

\section{REFERÊNCIAS}

Águas de Timon. Setor de operações e controle de perdas - AEGEA, 2019.

ASSOCIAÇÃO BRASILEIRA DE ENGENHARIA SANITÁRIA E AMBIENTAL - ABES. Perdas em sistemas de abastecimento de água: diagnóstico, potencial de ganhos com sua redução e propostas de medidas para o efetivo combate. São Paulo, SP, 2013.

BONATI, E.J.B, Análise da micromedição do volume de água potável domiciliar e sua influência no cálculo das perdas no sistema de distribuição. Disponível em: <https://repositorio.ufu.br/bitstream/123456789/14237/1/EJBBorgesDISPRT.pdf>. Acesso em: 09 set.2019.

CHEUNG, P.B (2013). Perdas de água: tecnologias de controle. João Pessoa: Editora da UFPB, 220p.

GONÇALVES, K. O; FERNANDES, L. L; GIRARD, L. Diagnóstico do serviço de abastecimento de água na percepção do usuário no município de Barcarena - Pará. Revista Monografias Ambientais REMOA v.14, n.1, Jan-Abr. 2015, p20-25.

MINISTÉRIO DAS CIDADES. Plano Nacional de Saneamento Básico - PLANSAB, 2013

SNIS (SISTEMA NACIONAL DE INFORMAÇÕES EM SANEAMENTO). Disponível em: $<$ www.snis.gov.br/>. Acesso em: 04 de setembro de 2019. 